\title{
EDUCAÇÃO, SOCIEDADE E CULTURA ${ }^{47}$
}

Marcelo Pessoa ${ }^{48}$

RESUMO: Nosso texto apresenta uma breve revisão dos problemas históricos da educação brasileira, alinhando a essa discussão, aspectos filosóficos, políticos, culturais e sociais. Após apresentar uma série de problemas na Educação brasileira, trazemos à tona a mediação, categoria de pensamento que ao mesmo tempo surge como parte do problema e também das soluções que podem ser dadas ao problema do sistema educacional brasileiro.

PALAVRAS-CHAVE: História da educação, mediação, sociedade.

ABSTRACT: Our text presents a brief review of the historical problems of Brazilian education, aligning to that discussion, philosophical aspects, political, cultural and social. After presenting a series of problems in the Brazilian education, bring up the mediation, category of thought at the same time is part of the problem and the solutions that can be given to the problem of the Brazilian educational system.

KEYWORDS: History of the education, Mediation, society.

\section{INTRODUÇÃO}

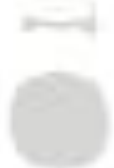

As práticas educativas geralmente tendem a fazer parte dos discursos políticos e da pauta de preocupações de primeira ordem de qualquer autoridade pública (particularmente em época de eleições, como será o ano de 2016) ou ainda de todo cidadão comum, independentemente se este se apresenta ou não à sociedade com o rótulo do "politicamente correto" estampado na face.

Isto é, em períodos eleitorais, alguns julgam ser "bacana" falar bem da educação, da segurança, do transporte e da saúde pública, e não é exatamente "bacana" falar mal de negros, gays, banqueiros, empreiteiros, ou de defensores desta ou daquela bandeira política etc.

A história social e cultural e os bastidores da educação estão verdadeiramente repletos de bons exemplos nesse sentido (de sujeitos inertes,

\footnotetext{
${ }^{47} \mathrm{O}$ presente texto é uma adaptação atualizada de um artigo apresentado no "IX Congresso de Educação Ambiental para o Desenvolvimento Sustentável" da VIII Convenção Internacional sobre Medio Ambiente y Desenvolvimiento, realizada em Havana, Cuba, de 08 a 12 de julho de 2013, com o apoio de bolsa BPO (Bolsa de Professor Orientador da Universidade do Estado de Minas Gerais - Brasil). Como, naquela ocasião, a publicação dos Anais (ou Memorias, como lá se denomina) se perdeu na burocracia do evento cubano, retomamos a discussão e publicamos neste periódico.

48 Docente na UEMG, Unidade Frutal. Pesquisador Bolsista CAPES/FaPP/UAB (2015). Desenvolve Projeto de Pesquisa com o apoio da UEMG e do Estado de Minas Gerais, via prêmio de fomento à pesquisa docente obtido por meio do Edital PAPq 08/2015.
}

\section{AKEDIA - VERSÕES, NEGLIGÊNCIAS E OUTROS MUNDOS ISSN: 2447-7656 - V. 2 - ANO 2 - FEVEREIRO, 2016 - FRUTAL - MG}


reativos e proativos), e principalmente daqueles, como eu, que acredita, mesmo antes do manifesto de Anísio Teixeira, Lourenço Filho, Fernando de Azevedo et. al., publicado em 1932, que "A educação é considerada em todos os seus graus como uma função social e um serviço essencialmente público a que o Estado é chamado realizar com a cooperação de todas as instituições sociais" (Manifesto dos Pioneiros da Educação Nova. In: PILETTI \& PILETTI, 2002a, p. 213). Logo, vemos que a Escola assim pressuposta é uma destas instituições que, ao lado de outros organismos socioculturais como a Família, a Igreja, o Exército, o Estado, atraem para si a responsabilidade de gerir os protocolos da boa intenção individual e coletiva quanto aos rumos da sociedade como um todo.

Neste sentido, este artigo soa meio que utópico ou fora da moda, tendo em vista que parece fazer ecoar em suas linhas o pensamento de Marx, quando este dizia que tudo que é sólido se desmancha no ar: "Tudo o que era sólido se desmancha no ar, tudo o que era sagrado é profanado, e as pessoas são finalmente forçadas a encarar com serenidade sua posição social e suas relações recíprocas" (Karl Marx. Manifesto do Partido Comunista, publicado originalmente em 21/02/1848). Noutros termos, o que estamos querendo dizer, é que estas instituições, ao lado de valores como honra, autoridade, respeito, dignidade etc., parecem, na pós-modernidade, itens retrógrados, anacrônicos, coisas de velhos mofando em asilos, visto que são comparáveis a quinquilharias socioculturais às quais ninguém parece querer dar mais atenção - ou seja, tudo que era sólido, está se desmanchando no ar dos tempos.

Mas, como o nosso foco é a academia e não a sociedade como um todo, perguntamo-nos muito sobre ela, a universidade: o que e como, de fato, a Escola Superior faz para ensinar determinados conteúdos? O que realmente podemos informar aos indivíduos bem intencionados de nossa sociedade quanto ao status quo da ensinança superior no Brasil, após quase um século de história de ensino universitário brasileiro ${ }^{49}$. O que podemos dizer sobre as

\footnotetext{
${ }^{49} \mathrm{O}$ ensino superior passou por importantes modificações a partir de 1930. Com a criação das primeiras universidades, superou-se a fase das escolas superiores isoladas, de caráter marcadamente profissional. A criação da Universidade de São Paulo, em 1934, tornou-se possível graças aos Estatutos das Universidades Brasileiras (Decreto $\mathrm{n}^{\circ}$ 19.851, de 14 de abril de 1931). Atendia-se, dessa forma, às
}

\section{AKEDIA - VERSÕES, NEGLIGÊNCIAS E OUTROS MUNDOS ISSN: 2447-7656 - V. 2 - ANO 2 - FEVEREIRO, 2016 - FRUTAL - MG}


práticas educativas reais que acontecem nas salas de aula? Será que o Estado atendeu ou decepcionou quanto ao atendimento das demandas postas em pauta pelos "pioneiros" do escolanovismo dispostas em seu Manifesto de 1932? A nossa sociedade, enfim, conseguiu ou está apta para atingir quaisquer das metas educacionais expressas nos moldes do que se relata pela Organização das Nações Unidas para a Educação, a seguir?

Aumentar o acesso tornou-se uma prioridade para a maioria dos Estados Membros e as crescentes taxas de participação na educação superior são uma tendência global ainda maior. Porém, grandes disparidades ainda persistem e constituem uma fonte maior de desigualdade. Governos e instituições devem estimular o acesso, a participação e o sucesso das mulheres em níveis de educação. Em acesso crescente, o ensino superior deve buscar as metas de igualdade, relevância e qualidade, simultaneamente. Igualdade não é simplesmente uma questão de acesso - o objetivo deve ser a participação e a conclusão efetiva, enquanto o estudante recebe um auxílio. Este auxílio deve incluir suporte financeiro e educacional adequados para aqueles que vivem em comunidades pobres e/ou marginalizadas (UNESCO, 2009).

Desse modo, na primeira etapa de nosso paper, apresentamos um pouco do estado da arte do sistema educacional, alguns dados históricos e problemas conjunturais que se fazem acompanhar pelo lastro do que acontece na política, em consequência da ideologia ou da instabilidade econômica.

Num segundo momento, nos preocupamos com propor fechos a algumas questões que se mostraram fundamentais no texto e, em seguida, damos ao leitor, as conclusões e nossas referências.

\section{O ESTADO DA ARTE DO SISTEMA EDUCACIONAL}

Não desconhecemos os esforços governamentais no estabelecimento de ações afirmativas para promover o incremento ao acesso e a fixação do discente na universidade. A Lei de Cotas, o Reuni, o Prouni, o FIES são exemplos dessas ações que, a partir do segundo mandato de Dilma Rousseff como Presidente do Brasil (primeiro mandato de governo começado em 2011,

\section{AKEDIA - VERSÕES, NEGLIGÊNCIAS E OUTROS MUNDOS ISSN: 2447-7656 - V. 2 - ANO 2 - FEVEREIRO, 2016 - FRUTAL - MG}


e o segundo, iniciado em 2015) foram catalisadas pelo slogan eleitoral que embalou sua campanha para o segundo pleito: "Brasil, Pátria Educadora":

Ao bradarmos "BRASIL, PÁTRIA EDUCADORA" estamos dizendo que a Educação será a prioridade das prioridades, mas, também, que devemos buscar, em todas as ações do governo, um sentido formador, uma prática cidadã, um compromisso de ética e um sentimento republicano. [...] Assim, à nossa determinação política se somarão mais recursos e mais investimentos. Vamos continuar expandindo o acesso às creches e pré-escolas, garantindo para todos o cumprimento da meta de universalizar, até 2016, o acesso de todas as crianças de 04 e 05 anos à pré-escola. Daremos sequência à implantação da alfabetização na idade certa e da educação em tempo integral. Condição para que a nossa ênfase no Ensino Médio seja efetiva porque, através dela buscaremos, em parceria com os Estados, efetivar mudanças curriculares e aprimorar a formação dos professores. Sabemos que essa é uma área frágil no nosso sistema educacional. [...] Vamos continuar apoiando nossas universidades, estimulando sua aproximação com os setores mais dinâmicos da nossa economia e da nossa sociedade (Fragmento do Discurso de posse de Dilma Rousseff, em 01/01/2015. Disponível em: http://www.promenino.org.br/noticias/reportagens/quais-os-desafios-dapatria-educadora-novo-slogan-do-governo-federal, acesso em 07/02/2016).

Contudo, nosso pensar e nosso falar por aqui, não se restringe ao questionar os vícios ou revelar as virtudes do sistema educacional, ou mesmo discorrer sobre os flertes com o fracasso que uma boa ideia, como a da "Pátria Educadora" aparenta ser, tem realizado por causa da instabilidade econômica (2015-2016), ou ainda falar sobre a contundência evidente das estatísticas de evasão ou de retenção no Ensino Superior, uma vez que vemos que, apesar disso tudo, das ideologias, dos discursos ou da Geografia do problema, o tempo presente repete as mesmas assimetrias do passado, seja pela constatação de que:

A evasão de estudantes é um fenômeno complexo, comum às instituições universitárias no mundo contemporâneo. Nos últimos anos, esse tema tem sido objeto de alguns estudos e análises, especialmente nos países do primeiro mundo, e têm demonstrado não só a universalidade do fenômeno como a relativa homogeneidade de seu comportamento em determinadas áreas do saber, apesar das diferenças entre as instituições de ensino e das peculiaridades sócioeconômico-culturais de cada país (VELOSO, 2000, p. 14).

\section{AKEDIA - VERSÕES, NEGLIGÊNCIAS E OUTROS MUNDOS ISSN: 2447-7656 - V. 2 - ANO 2 - FEVEREIRO, 2016 - FRUTAL - MG}


Seja pelo caráter altamente contestável dos dados do Governo, divulgados no mês de julho do ano de 2015, dizendo que:

Desde 1990, o Brasil reduziu em $64 \%$ a evasão escolar de crianças e adolescentes no ensino fundamental, passando de $19,6 \%$ dos alunos matriculados para $7 \%$ em 2013. E mais: a taxa de analfabetismo caiu $88,8 \%$ na faixa entre 10 e 18 anos de idade, passando de $12,5 \%$, em 1990, para 1,4\% em 2013, de acordo com dados do Pesquisa Nacional de Amostra por Domicílios (Pnad) (Disponível em: http://www.brasil.gov.br/cidadania-e-justica/2015/07/brasil-reduz-73-dotrabalho-infantil-e-64-da-evasao-escolar, acesso em 02/02/2016).

Mas, por que contestável? A partir do que e com o que devemos nos preocupar? Com os dados do INEP (2010), que no documento intitulado "Resumo Técnico Censo da Educação Superior de 2010", não traz uma palavra sequer sobre a ideia de "evasão" ou de "retenção" no Ensino Superior?

Em estudo sobre a permanência estudantil na UFFS - Universidade Federal da Fronteira Sul, Campus de Erechim, foram examinados dados sobre evasão dos cursos e da Instituição, no período compreendido entre os anos de 2010 a 2012. Observou-se na pesquisa que a média de evasão no Campus Erechim, nos seus três primeiros anos de funcionamento, foi de aproximadamente $\quad 37,9 \% \quad$ (RONSONI, 2014, Disponível em http://37reuniao.anped.org.br/wp-content/uploads/2015/02/Trabalho-GT143932.pdf).

Segundo o professor Oscar Hipólito, reitor da Universidade Anhembi Morumbi, Vice-Presidente Acadêmico da Laureate Brasil e curador do II Seminário Evasão no Ensino Superior Brasileiro (realizado em 21/10/2015): "no Brasil, a média (de evasão) entre as universidades públicas e privadas é de 21 ou $22 \%$ ao ano". Sob a perspectiva da quantidade de alunos matriculados, Hipólito lembrou que, como o número total de estudantes, à época do Seminário, era de cerca de 07 milhões, a taxa de evasão representaria um total de 1,4 milhão de alunos: "No caso das escolas públicas, a porcentagem de evasão é menor e gira em torno de $12 \%$. Já, nas instituições privadas, é de $25 \%$ ". No entanto, sabendo que o número de alunos matriculados em universidades particulares é muito maior do que nas públicas, os $25 \%$ evadidos

\section{AKEDIA - VERSÕES, NEGLIGÊNCIAS E OUTROS MUNDOS ISSN: 2447-7656 - V. 2 - ANO 2 - FEVEREIRO, 2016 - FRUTAL - MG}


das particulares representam uma quantidade de estudantes muito maior do que os outros $12 \%$ verificados nas públicas (Dados do II Seminário sobre evasão no Ensino Superior compilados de http://noticias.universia.com.br/destaque/noticia/2015/10/06/1132040/indiceevasao-ensino-superior-brasil-cerca-21-inscreva-seminario.html, acesso em 07/02/2016).

Ao lado desses dados recentes, temos ainda a séria histórica dos fatos, dizendo que, em 2001 (dados do IBGE, computados entre 2001 e 2009), tivemos 15 milhões de estudantes ingressantes no Ensino Superior, o que não quer dizer muito, se vermos que entre 2001 e 2009, houve uma escalada de evasão ou de retenção de discentes que não se formaram na faixa média de $40 \%$ ou $50 \%$.

Indiscutivelmente esses números elevam nosso IDH (índice de desenvolvimento humano) e também transformam o nosso povo predominantemente semiletrado em intelectuais esplêndidos. Após quatro anos morando nos Estados Unidos, o outrora unânime e hoje controverso literato brasileiro Monteiro Lobato, escreveu assim, sobre a possibilidade de voltar a viver no Brasil (ele viveu alguns anos nos Estados Unidos, durante a década de 1920, retornando ao Brasil, em 1931):

Eu, por mim, não sairia mais daqui, porque o Brasil torna-se grotesco visto de longe. Infelizmente, a família é um cordão umbilical que me prende a essa cataplasma. Só agora meço em extensão o atraso, e a estupidez maior ainda, da nossa gente. Somos África pura (Monteiro Lobato. In: SODRÉ \& PAIVA, 2002, p. 15).

Igualmente, nem de longe vamos tocar no delicado assunto da valorização econômica do profissional da educação, já que no ano de 2012 assistimos uma das maiores paralisações da história do funcionalismo público federal e também dos profissionais do ensino público superior no Brasil, protagonizada em massa pelas universidades federais e por algumas universidades estaduais isoladas:

No caso dos professores, inicialmente, nos tempos da educação jesuítica (período colonial), eles eram valorizados como trabalhadores

\section{AKEDIA - VERSÕES, NEGLIGÊNCIAS E OUTROS MUNDOS ISSN: 2447-7656 - V. 2 - ANO 2 - FEVEREIRO, 2016 - FRUTAL - MG}


intelectuais, na medida em que detinham todo o saber sistematizado veiculado na Colônia. Após a expulsão dos jesuítas do país, em 1759, surge, em 1772, uma "política de oferta direta da instrução gratuita através de professores assalariados" (MONLEVADE, 2001, p. 23) ${ }^{50}$ : os professores das "aulas régias" ou professores de disciplinas específicas, improvisados e mal pagos. Tem-se, assim, uma desvalorização do trabalho docente: de trabalhadores intelectuais, esses "profissionais" passam à condição de intelectuais trabalhadores, que recebem um "salário" (precário) pago pelo seu trabalho (MEC, 2006, p. 17).

Não tocaremos em tais assuntos, não por que não sejam relevantes, mas por que estas são, ou pelo menos deveriam ser, questões sine qua non para o exercício docente e jamais deveriam sequer aparecer como "problema" numa pauta de discussão tão despretensiosa como a nossa - já nos bastaria aqui perceber que o sistema educacional apresenta sinais claros de corrosão, não precisando de mais nada para que se declare a iminência apátrida de nossa educação.

Vamos, aqui, então, apenas refletir sobre a transmissão de conteúdos, a natureza desta ou daquela disciplina. Enfim, não iremos restaurar nada e nem tocar as feridas. Apenas faremos sugestões e, quando muito, poucas considerações modestas sobre a área da Educação como um todo.

\section{RESOLUÇÕES E DESFECHOS DAS QUESTÕES}

A problematização educacional e, consequentemente, das informações aqui apresentadas sobre o assunto, nos diz que o que aqui apresentamos é mais que uma preocupação social, política, filosófica, é, sobretudo uma questão geral da área da Educação e se constitui num tipo de dificuldade ao mesmo tempo em que específica de um ponto geográfico, global, sob o ponto de vista teórico ou existencial.

Por mais bem intencionadas que sejam as propostas de melhorias educativas formuladas e motivadas a partir de premissas como a da Pátria Educadora, da política de cotas, o FIES etc., o desajuste na área da Educação ainda persiste, uma vez que é praticamente inevitável o confronto delas (das

\footnotetext{
${ }^{50}$ A referência à qual o texto alude é: MONLEVADE, João. 13 lições sobre fazer-se educador no Brasil. Brasília: Idea Editora, 2001 (In: MEC, 2006).
}

\section{AKEDIA - VERSÕES, NEGLIGÊNCIAS E OUTROS MUNDOS ISSN: 2447-7656 - V. 2 - ANO 2 - FEVEREIRO, 2016 - FRUTAL - MG}


ações e das ideologias em seu entorno) com questões relacionadas à eficiência aplicada e análise dos resultados objetivos frente às metas governamentais:

Uma das maiores preocupações dos educadores é, sem dúvida, o desenvolvimento intelectual dos alunos, visando à autonomia de pensamento, à facilidade de elaboração e expressão de ideias e à formação do pensamento crítico. Mas, a escola, não tem tido muito êxito neste aspecto e, sem dúvida, isto se deve, em grande parte, à maneira como o processo ensino-aprendizagem é conduzido (VALENTE, 2007, p. 263).

É fato que o exposto por Valente (2007) também resvala no território da mediação no ensino e, especificamente, sobre o modo de transmissão de conteúdos na Escola. Contudo, para dinamizarmos o foco de nosso breve debate neste fórum sobre conteúdos e os seus modos de transmissão, poderíamos estabelecer dois fronts básicos que são aparentemente paradoxais no processo de ensino-aprendizagem.

De um lado, então, a partir do prisma do processo de ensinar e aprender vê-se que a escola trabalha seus conteúdos, ou pelo menos deveria trabalhar, com o propósito de formar cidadãos críticos e transformadores para a sociedade.

E, de outro lado, que a assim denominada "academia" - cenário mais em voga neste texto -, por alguma razão, já que fracassa em seus propósitos basilares (quer seja considerada pela ótica das demandas mercadológicas que atende, quer sob o ponto de vista da formação cidadã que proporciona), movimenta suas ferramentas do conhecimento no sentido de construir um tipo de sujeito, ao invés de sábio, cada vez mais "adestrado" e apto a se conformar com o establishment, com o status quo e com todas as demais categorias socioculturais do gênero cooptação em tais contextos cabíveis.

A razão de isso ser assim supomos que resida tanto em fatores pontuais, como a episódios de certo desinteresse do estudante pelo aprendizado ("É muito pouco provável a ocorrência de aprendizagem quando o aluno na tem interesse em aprender", VALENTE, 2007, p. 281), quanto em

\section{AKEDIA - VERSÕES, NEGLIGÊNCIAS E OUTROS MUNDOS ISSN: 2447-7656 - V. 2 - ANO 2 - FEVEREIRO, 2016 - FRUTAL - MG}


fatores conjunturais, como as intervenções desastrosas do Estado no contexto da Educação:

A reforma de 68, a partir da pressão dos movimentos estudantis e de professores, sob a tutela do Estado, mas que não contou com a presença de seus elementos mais críticos e criativos que haviam sido afastados pelo regime militar, levou à intensa centralização, estabeleceu mecanismos de controle burocráticos, excluindo os docentes dos centros de decisão, levando-os a perder a visão de conjunto da instituição e reforçando 0 isolamento das unidades acadêmicas (SARMENTO, 1991; MORAES, 1999. In: PEREIRA, 2003, p. 30).

Essa macroestrutura ou superestrutura (recorremos a esta expressão, a fim de mantermos a vinculação marxista imposta à discussão desde o início) é idealizada e de dupla dissociação: de uma parte, do ensino em relação aos seus gestores e, de outra parte, da dissociação do ensino com a tomada de consciência sociocultural. Assim, atingiram-se, em certos momentos da história da Educação, picos de desinteresse e deseducação com intensidade tão elevadas que, em alguns teóricos do sistema educacional, chegou-se mesmo a propor uma desescolarização, isto é, um fim da escola face à distância da realidade que dentro dela se constrói:

A teoria da desescolarização constituiu uma posição extremista e até reacionária em relação à escola. Seu principal representante, o já falecido Ivan Illich, foi por muitos anos Vice-reitor da Universidade Católica de Ponce, Porto Rico, e fundador do Centro de Estudos sobre educação em Cuernavaca (México), em 1963. Seus trabalhos foram amplamente lidos na América Latina, especialmente na década de setenta. Em sua obra mais importante, Uma Sociedade sem Escolas (1973), I. Illich passa a engrossar o mar de acusações à escola oficial, e sua proposta teve resultados interessantes para aqueles que desejavam desmistificar o discurso oficial dos intelectuais orgânicos do Estado capitalista (PUENTES, 2004, p. 48).

Difícil sabermos em qual dos dois polos nos encontramos (quando formamos cidadãos, eles são críticos ou alienados?). O sistema de Ensino Superior está contaminado de uma produtividade acadêmica praticamente fordista. Alunos saem hoje das universidades como se estivessem numa linha de montagem. Professores não atuam como seres humanos, mas como gerentes e braços alongados do "dono", isto é, são hoje não mais que

\section{AKEDIA - VERSÕES, NEGLIGÊNCIAS E OUTROS MUNDOS ISSN: 2447-7656 - V. 2 - ANO 2 - FEVEREIRO, 2016 - FRUTAL - MG}


capatazes brandindo seu chicote acadêmico, vociferando a hegemonia de um conhecimento que se reconhece falido ou, no mínimo, inoperante sobre o todo da sociedade, mas que se legitima pelo uso das próprias irrisões que contesta:

A Grécia Clássica pode ser considerada o berço da pedagogia. A palavra paidagogos significa aquele que conduz a criança, no caso, o escravo que acompanha a criança à escola. Com o tempo, o sentido se amplia para designar toda a teoria da educação. De modo geral, a educação grega está constantemente centrada na formação integral corpo e espírito - mesmo que, de fato, a ênfase se deslocasse ora mais para o preparo esportivo ora para o debate intelectual, conforme a época e lugar (VALENTE, 2007, p. 159).

Ao contrário do que lemos acima, nosso aparato educacional hoje em funcionamento não faz muito mais do que adestrar nossos estudantes. Devidamente adestrados pela ditadura quantitativa da produção científica, nós, os professores, impedidos ou sem tempo para pensar, adestramos nossos jovens para "passarem de ano", enquanto isso, num nível anterior ao do Ensino Superior, os adestramos para "passarem no vestibular" e, num rigor de crueldade do processo, uma vez na universidade, os adestramos "para obterem êxito no ENADE" e demais exames de proficiência profissional "OAB, CREA, CREF etc." e, finalmente, o auge da coisa se celebra quando, ao invés de formarmos homens melhores, temos que nos preocupar em adestra-los "para se saírem bem no mercado de trabalho".

\section{COMO CONCLUIR ALGO QUE NÃO TEM FIM?}

Se considerarmos que dentro do conceito de aprendizagem, um de seus princípios fundadores é o de que a aprendizagem efetivamente só acontece quando se expõe o indivíduo ao conhecimento, teremos o grau máximo de eficácia das estratégias de educação ambiental num nível de conformidade quando conseguirmos aproximar ilimitadamente o educando daquele tipo de conteúdo que se deseja que ele deva dominar.

Teremos de recombinar o DNA da educação com o da necessidade de sobrevivência. Retirar dela lentamente os genes da prática conservacionista e

\section{AKEDIA - VERSÕES, NEGLIGÊNCIAS E OUTROS MUNDOS ISSN: 2447-7656 - V. 2 - ANO 2 - FEVEREIRO, 2016 - FRUTAL - MG}


inserir, paulatinamente, os fragmentos da educação nos moldes da conformidade, indivíduo por indivíduo, casa por casa.

Ensinar a pensar é sempre mais difícil? Portanto, saiamos igualmente das amarras dessas palavras, e imaginemos que mais difícil ainda talvez seja "pensar para ensinar".

Pensar o processo histórico de ensino-aprendizagem é sempre importante. Mas, refletir e propor novas possibilidades e abordagens talvez nos apresente novos caminhos a seguir sobre a Educação, sobre o mundo, sobre nossa gente, enfim, e que não seja naquele tom pejorativo relacionado à "África pura", como nos houvera sugerido Monteiro Lobato.

Em nosso caso, repensar a Educação sob a ótica de terminologias como a da paidea é o foco onde reside nossa parcela de contribuição para um tipo de desenvolvimento que se entenda qualitativamente interessante para a sociedade. Do mesmo modo, nosso pensamento caminha na direção de se construir etapas exequíveis para a consolidação de uma economia forte e para a reversibilidade dos índices de retenção e evasão escolar que assolam de modo negativo o ambiente da Educação no Brasil.

\section{REFERÊNCIAS}

MEC - Ministério da Educação. Secretaria de Educação Básica - Conselho Escolar e a valorização dos trabalhadores em educação. Brasília - DF, 2006. Disponível http://portal.mec.gov.br/seb/arquivos/pdf/Consescol/cad\%208.pdf.

INEP - Instituto Nacional de Estudos e Pesquisas Educacionais Anísio Teixeira. Censo da Educação Superior 2010 - Resumo Técnico. Disponível em http://download.inep.gov.br/educacao superior/censo superior/resumo tecnico /resumo tecnico censo educacao superior 2010.pdf.

PEREIRA, Fernanda Cristina Barbosa. Determinantes da evasão de alunos e os custos ocultos para as instituições de ensino superior: uma aplicação na universidade do extremo sul catarinense. UFSC: Florianópolis, 2003 (tese de doutorado).

PILETTI, Claudino \& PILETTI, Nelson. Filosofia e História da Educação. São Paulo: Ática, 2002a.

PILETTI, Claudino \& PILETTI, Nelson. História da Educação. São Paulo: Ática, $2002 b$.

\section{AKEDIA - VERSÕES, NEGLIGÊNCIAS E OUTROS MUNDOS ISSN: 2447-7656 - V. 2 - ANO 2 - FEVEREIRO, 2016 - FRUTAL - MG}


PUENTES, Roberto Valdés. Os Estudos das Teorias Educativas na América Latina. São Paulo: UNIFEOB, 2004.

RONSONI, M. L. Permanência e evasão de estudantes da UFFS Campus Erechim. In: PEREIRA, T. I. (Org.). Universidade pública em tempos de expansão: entre o vivido e o pensado. Erechim: Evangraf, 2014, p. 17-31.

SODRÉ, Muniz \& PAIVA, Raquel. O Império do Grotesco. Rio de Janeiro: MAUAD, 2002.

UNESCO. As Novas Dinâmicas do Ensino Superior e Pesquisas para a Mudança e o Desenvolvimento Social. Conferência Mundial sobre o Ensino Superior. Paris, França, 08 de julho de 2009.

VALENTE, Nelson. Não Adapte. Adote. São Paulo: Intermedial, 2007.

VELOSO, Thereza Cristina M. A. A Evasão nos Cursos de Graduação da Universidade Federal de Mato Grosso, Campus Universitário de Cuiabá 1985/2 a 1995/2 - Um processo de Exclusão. UFMT: Cuiabá, 2000 (dissertação de mestrado). In: PEREIRA,

Fernanda Cristina Barbosa. Determinantes da evasão de alunos e os custos ocultos para as instituições de ensino superior: uma aplicação na universidade do extremo sul catarinense. UFSC: Florianópolis, 2003 (tese de doutorado).

\section{AKEDIA - VERSÕES, NEGLIGÊNCIAS E OUTROS MUNDOS ISSN: 2447-7656 - V. 2 - ANO 2 - FEVEREIRO, 2016 - FRUTAL - MG}

